\title{
A prática odontológica em Unidades Básicas de Saúde em Feira de Santana (BA) no processo de municipalização da saúde: individual, curativa, autônoma e tecnicista
}

\author{
The odontological practice in the Basic $\mathrm{H}$ ealth \\ Units in Feira de Santana, Bahia, in the health \\ municipalization process: individual, autonomous, \\ curative and technical activities
}

Dayliz Quinto Pereira 1

Júlio César M otta Pereira 1

M arluce M aria Araújo Assis 1

1 Programa de

Pós-Graduação em Saúde

Coletiva, Universidade

Estadual de Feira

de Santana,

Departamento de Saúde.

Av. Dr. Getúlio Vargas 644,

sala 14, 44025-010, Centro,

Feira de Santana BA.

jdquinho@uol.com.br
Abstract The main objective of this present study has been the description and analysis of the odontological practice in the $U$ nidades Básicas de Saúde (Basic H ealth U nits) in Feira de Santana, Bahia, in the health municipalization process. It is a qualitativeresearch with a descriptive and exploratory characteristic. The empirical data were analyzed from a semistructured interview with dental surgeons ( 10 professionals altogether) and a non-participant observation in 3 $\mathrm{BH}$ U. The empirical material treatment was based on the Bardin's (1979) and Minayo's(1999) syllabus, from which, it was ought to unveil the visible and concealed contents from the intervi ewees' speeches and have a greater understanding of the odontological procedures in the public health system. The outcome shows that the professional dental surgeon is not introduced into the municipalization process, benefiting individual, autonomous, curative and technical activities. We have deduced that the odontological practice present in the $\mathrm{BHU}$ in Feira de Santana, needs to be (re) built in order to achieve the goals indicated by the "SU S" ( N ational Public H ealth System). And mainly, having the professional dental surgeon playing an active role in this process, leading alternative practices concerned with the promotion, prevention, treatment and rehabilitation of the oral health.

Key words $\mathrm{O}$ dontological practice, $\mathrm{H}$ ealth municipalization, Basic $\mathrm{H}$ ealth $\mathrm{U}$ nits
Resumo 0 presente estudo teve como objetivo central a descrição e análise da prática odontológica nas U nidades Básicas de Saúde (UBS) em Feira de Santana, no processo de municipalização da saúde. Tratase de uma pesquisa qualitativa, do tipo descritiva-exploratória. Os dados empíricosforam analisados a partir de en trevista semiestruturada com cirurgi ões- denti stas ( 10 profissionais) e de observação não participante em 3 U BS. 0 tratamento do material empírico foi baseado na análi se de conteúdo de Bardin (1979) e M inayo (1999), em que se buscou desvendar os conteúdos manifestos e latentes dos discursos dos entrevistados, e uma maior compreensão da prática odontológica na rede básica. Os resultados obti dos demonstram que o profissional CD não se inseriu no processo de municipalização, e encontra-se ain da exercendo uma prática pautada no modelo tradicional de aten ção à saúde bucal, privilegiando ações individuais, autônomas, curativas e tecnicistas. Concluímos que a prática odontológica nas UBS-FS precisa ser (re) construída, para atingir os objeti vos preconizados pelo SU S. E, principalmente, 0 profissional CD se inserir como sujeito do processo, apontando para práticas alternativas voltadas para a promoção, prevenção, tratamento e reabilitação da saúde bucal.

Palavras-chave Prática odontológica, M unicipalização da saúde, U nidade Básica de Saúde 


\section{Introdução}

0 presente estudo surgiu do nosso interesse em conhecer a atuação clínica do cirurgião-dentista sobre as práticas odontológicas nos serviços de saúde do município de Feira de Santana (BA), uma vez queeste profissional éresponsável pela saúde bucal das pessoas da sua comunidadeeos seus conhecimentos devem ser direcionados para tal fim. Tomaremos como eixo condutor, a implantação do processo de municipalização da saúde, com baseno caráter político e social dos serviços de saúde no Brasil e em Feira de Santana, a partir de 1997, com a inserção do município no processo demunicipalização, encontrando-se atualmentena gestão plena da atenção básica.

Ao estudar a prática do cirurgião-dentista a partir do processo demunicipalização da saúde no município deFeira de Santana, énecessário tomar como eixo orientador a reformulação do setor saúdeno Brasil, nas décadas de 1980 e 1990, pois, nosúltimos 20 anos, tem sido discutida, refletida e analisada a necessidade de tran sformação do sistema de saúde, desdobrando-se, na prática, em propostas queargumentam pela reestruturação do modelo assistencial vigente, o qual vem se constituindo historicamente no médico assistencial privativista, baseado na demanda espontânea ena prática liberal. Diante dessa perspectiva Arouca (1988) afirma quea proposta da Reforma Sanitária Brasileira representa, por um lado, a indignação contra as precárias condições de saúde, o descaso acumulado, a mercantilização do setor, a incompetência e o atraso e, por outro, a possibilidade da existência de uma viabilidade técnica euma possibilidade política de enfrentar o problema.

No início da década de 1990, Feira deSantana começou a adotar diretrizes jurídicas na tentativa de viabilizar a construção do SU S no município, acompanhando, dessa forma, todo o movimento nacional quebuscava uma nova organização no sistema de saúde brasileiro, fundada na descentralização. A reestruturação administrativa da Secretaria M unicipal de Saúde aconteceu em 1993 e 1995 ea habilitação para o SU Sna condição de Gestão Plena da Atenção Básica, em 1997 (Assis, 1998b).

\section{A fundamentação teórica}

Para discutirmos a fundamentação teórica do estudo, delimitamos como pressuposto orientador que a prática odontológica tem raízes históricas, culturais esociais na formação do cirurgião-dentista, pautada no model o flexneriano ou medicina cientifica, constituindo-se em uma prática individual, curativa, tecnicista, especializada ebiologicista.

Atéas primeiras três décadas do século 18, a odontologia, por não ser considerada ciência e/ ou arte, era exercida por charlatões que estabeleciam suas bancas nas feiras. Essa situação perdurou até quando em 1728 o cirurgião-dentista PierreFauchard lançou os três volumes deLeChirurgien-dentiste, com relato de sua longa experiência em extração descrevendo em termos científicos a anatomia bucal (Fernandez, 2001). As obras do referido autor podem ser consideradas uma revolução odontológica, permitindo uma analogia, em termos de sua importância, com a Revolução Francesa.

Como sabemos, a odontologia advém daárea de conhecimento do campo das ciências médicas e, por conseguinte, tem seu marco conceitual e seu alicerce na medicina científica. 0 seu paradigma começa quando se institucionaliza o Relatório Flexner que pretendeu a reformulação do ensino médico no século 20 na FaculdadedeM $\mathrm{e}$ dicina de Johns H opkins, e publicado em 1910, conjuntamente com a Fundação Carneger dos Estados Unidos (M endes, 1985). O Relatório Flexner apresenta as seguintes sugestões: 1) definição de padrões de entrada e ampliação, para quatro anos, da duração dos cursos; 2 ) introdução ao ensino laboratorial; 3) estímulo à docência em tempo integral; 4) expansão do ensino clínico, especialmente hospital; 5) vinculação das escolas médicas às universidades; 6) ênfase na pesquisa biológica como forma de superar a era empírica do ensino médico; 7) estímulo à especialização médica; 8) vinculação da pesquisa ao ensino; e9) controledo exercício profissional pela profissão organizada.

Asfaculdades brasileiras demedicina, no pe ríodo de 1940 a 1950, passaram por uma grande reforma na estrutura curricular, tendo como baseo modelo flexneriano, voltado para ciclos básicosnos primeiros anos deensino; ciclos clínicos nos anos subseqüentes e concentração do ensino prático no ambientehospitalar.

Surge o modelo de prática odontológica conhecida como odontologia científica ou flexneriana ( $M$ endes, 1985). Esse modelo expressa um conjunto queenvolveo mecanicismo, biologicismo, individualismo, especialismo, especialização, exclusão de práticas alternativas, tecnicista do ato odontológico, com ênfasena odontologia curativa e de gestão tecnocrática. 
A prática odontológica é, portanto, baseada nesse modelo, embora demonstre ser ineficaz, na medida em que não responde, em níveis significativos, aos problemas de saúde bucal da população, e in eficiente, uma vez que é de alto custo e baixíssimo rendimento, apesar de apresentar um grande desenvolvimento científico etecnológico, experimentado pela odontologia brasileira. A prática odontológica, ao final do século passado, vem carregando uma grande contradição, queé retratada na evolução técnica da odontologia, com novos equipamentos, medicamentos e procedimentos mais simplificados, porém com seu alcance social mínimo, o que torna cientificamente questionáveis as medidas de interven ção, fazendo com queo modelo assistencial seja dealta complexidadee com ênfase no enfoquecurativo.

Como tudo, a prática odontológica está intimamenterelacionada ao indivíduo e, dependendo de suas condições, pode causar impacto negativo no bem-estar geral do ser humano. Ressaltamos, no entanto, quea luta pela democracia epela extensão da cidadania no processo de construção do Sistema Ú nico de Saúde, via descentralização/municipalização, impulsionou mudanças nas práticas, e nas concepções sobre o que deve fazer a odontologia brasileira. Questionamos, também, seépossível visualizar no trabalho cotidiano do profissional do serviço público essa compreensão. Quais são os reflexos do atendimento odontológico à população, a partir da atenção integral e das estratégias descentralizadoras, como princípios doutrinários do SUS?

\section{Caminhar metodológico}

Para este estudo utilizamos a abordagem da pesquisa qualitativa do tipo exploratória, por possibilitar responder a questões sociais, com a compreensão dos seres humanos e da natureza, ede suas relações intra-subjetivas e com a realidade social, pois como enfatiza M inayo (2000) a realidade social éo próprio dinamismo da vida individual e coletiva com toda a riqueza de significados dela transbordante.

E énessa perspectiva que buscamos aprofundar a complexidade dos fenômenos, fatos e processos particulares eespecíficos de grupos mais ou menos del imitados em extensão e capazes de serem abrangidos intensamente ( $M$ inayo e Sanches, 1998).

A pesquisa foi realizada em Feira deSantana, distando $110 \mathrm{~km}$ deSalvador, capital da Bahia, lo- calizada na zona do semi-árido eocupando uma extensão territorial de $1.344 \mathrm{~km}^{2}$. 0 município situa-sena região Norte do Estado edestaca-se como o mais importante entroncamento rodoviário do N orte-N ordestedo país, permitindo um grandefluxo de pessoas e bens ( produtos) vindos dos mais diversos pontos. Estima-se que tenha uma população de aproximadamente 470.719 habitantes (IBGE, 2000).

Osórgãos responsáveis pela saúde no município são: a Segunda Diretoria Regional de Saúde (2a DIRES) ea Secretaria M unicipal deSaúde, órgãos vinculados à esfera estadual e municipal, respectivamente.

A Secretaria M unicipal deSaúde deFeira de Santana (SM S-FS) foi criada em 1990, pela lei $n$. 1.349, etem as seguintes divisões administrativas: Enfermagem, O dontologia, M edicina, Vigilância Sanitária, Controle Epidemiológico, Controle Financeiro, Administrativo das U nidades deSaúdeeI nformação em Saúde.

N as U BS-FS são desenvolvidos os serviços: consultas médicas, atendimento odontológico, imunização, atividades realizadas pel a equipe do PACS (Programa de Agentes Comunitários) e consultas de enfermagem vinculadas às ações programáticas na aten ção a grupos específicos da população (Feira de Santana, 1999).

Em dezembro de2000, FeiradeSantana apresentava 33 U nidades Básicas de Saúde da rede municipal; destas, 29 prestam atendimento odontológico. A sede, conta com 21 UBS, com 36 cirurgiões-dentistas, sete com duplo vínculo de trabalho Estado/município, e uma voluntária, perfazendo um total de 44 cirurgiões- dentistas. $\mathrm{N}$ as outras oito UBS dos distritos, temos $11 \mathrm{ci}$ rurgiões-dentistas, dois com duplo vínculo Estado/município, num total de 13 profissionais. Além desses profissionais que atuam na rede básica, temosuma CD na auditoria, quatro em programas depreven ção a escolares e um afastado para curso, conformedocumento cedido pela Divisão de O dontologia daSM S/FS.

A Divisão de O dontologia se caracteriza pela seção de Reabilitação Bucal e a dePrevenção Bucal.

Para uma melhor definição do objeto deestudo desenvolvemos uma pesquisa exploratória. $N$ essa etapa, fizemos contatos com a equipe da Secretaria M unicipal de Saúde de Feira de Santana para definir melhor o recorte do objeto eas estratégias teórico-metodológicas. Para tanto, realizamos um levantamento que nos permitiu identificar a rede básica do município, ea distribuição dos cirurgiões-dentistas nas referidas 
unidades.

Esse primeiro levantamento possibilitou a escolha das U BS, como uma primeira aproximação ao campo empírico da pesquisa, no qual procedemos à observação geral em dez UBS. 0 crité rio de sel eção das UBS foi a existência do serviço de odontologia, seguindo o roteiro: 1) condições defuncionamento da redebásica; 2) estruturafísica; 3) quantificação, especificação e as condições de uso dos equipamentos; 4) número de profissionais de nível superior, técnico eelementar; 5) qualificação do profissional cirurgiãodentista; 6) número de atendimentos odontológicos; 7) carga horária de distribuição deprofissionais por turno.

0 atendimento odontológico édiário em todas as unidades, de segunda a sexta-feira, com exceção de uma queatende de segunda a quinta-feira. A pesar de ser determinado pela SM S que todas as U BS atendam nos cinco dias da semana; observamos queisso não acontece, assim como 0 horário, que é estipulado para ser das 7:00 às 12:00 edas 13:00 às 17:00 horas, não corresponde à realidade. A penas um cirurgião-dentista (CD) trabalhava nesse momento da pesquisa de campo. O utra questão écom relação à jornada de trabal ho do $C D$, que deveria ser de 30 horas semanais, ou dezoito procedimentos dia e que não acontece. As horas estabelecidas no contrato eos procedimentos odontológicos são interpretados de várias formas pelos profissionais. Uns atendem por número de pacientes, eoutros, por procedimentos odontológicos em cada paciente.

Deposse do levantamento de dados realizado na pesquisa exploratória, partimos para a escolha das U BS que fariam parte do nosso estudo. Paraisso foram estabelecidos al guns critérios: 1) ter atendimento odontológico, nos doisturnos, para adultos e crianças; 2) o serviço de odontologia deveria ofertar as atividades de prevenção, restaurações eexodontia.

\section{Unidade Básica de Saúde A}

Essa unidade foi fundada em 15 de fevereiro de 1986, surgindo das rei vindicações advindas da comunidade local, e só foi fortalecida após convênio com a Prefeitura M unicipal de Feira de Santana. Em 1998, passou a ser cessão de uso da SM S/FS, conforme determina a gestão da atenção básica (Quadro 1).

\section{Unidade Básica de Saúde B}

Esta unidade tem caráter filantrópico, foi inaugurada em 1985, com uma pequena estrutura física, que aos poucos foi sendo ampliada com a ajuda da comunidade ( $Q$ uadro 2).

\section{Unidade Básica de Saúde C}

Primeiro Centro de Saúde M unicipal de Feira de Santana, funcionava em um antigo hospital. Não faz trabalhos educativos, nem o programa de planejamento familiar, porém desenvolve ações do Programa Agentes Comunitários de Saúde (PACS) (Quadro 3).

Considerando que as estratégias de coleta de dados devem possibilitar uma aproximação com a prática odontológica, objeto deste estudo, optamos pela utilização da técnica de observação não-participante, e da entrevista semi-estruturada com os sujeitos (cirurgiõesdentistas) que atuam nas referidas U BS.

U tilizamos, portanto, o roteiro de observação não-participante, em que o foco principal foi a atividade prática do cirurgião-dentista na UBS, levando em conta os seguintes pontos: fluxo da demanda espontânea e resolutividade do serviço de odontologia; 0 aten-

Quadro 1

Caracterização dos cirurgiões- dentistas que prestam serviços

na Unidade Básica de Saúde A - Feira de Santana, dezembro/2000

\begin{tabular}{llcc}
\hline Área de atuação & \multicolumn{1}{c}{$\begin{array}{c}\text { Vínculo } \\
\text { empregatício }\end{array}$} & $\begin{array}{c}\text { Tempo de experiência } \\
\text { profissional }\end{array}$ & $\begin{array}{c}\text { Número de } \\
\text { cirurgiões-dentistas }\end{array}$ \\
\hline Exodontia & SESAB/Município & 23 anos & 01 \\
Dentística & M unicípio & 9 anos & 01 \\
Programa deprevenção & SESAB/M unicípio & 22 anos & 01 \\
\hline
\end{tabular}


Quadro 2

Caracterização dos cirurgiões- dentistas que prestam serviço

na U nidade Básica de Saúde B - Feira de Santana, dezembro/2000

\begin{tabular}{lccc}
\hline Área de atuação & $\begin{array}{c}\text { Vínculo } \\
\text { empregatício }\end{array}$ & $\begin{array}{c}\text { Tempo de experiência } \\
\text { profissional }\end{array}$ & $\begin{array}{c}\text { Número de } \\
\text { cirurgiões-dentistas }\end{array}$ \\
\hline Odontopediatria & SESAB & 23 anos/12 anos & 02 \\
Clínico geral & SESAB & 8 anos/10 anos & 02 \\
Periodontia & Voluntária & 3 meses & 01 \\
\hline
\end{tabular}

Quadro 3

Caracterização dos cirurgiões-dentistas que prestam serviços na U nidade Básica de SaúdeC - Feira de Santana, janeiro/2001

\begin{tabular}{lccc}
\hline Área de atuação & $\begin{array}{c}\text { Vínculo } \\
\text { empregatício }\end{array}$ & $\begin{array}{c}\text { Tempo de experiência } \\
\text { profissional }\end{array}$ & $\begin{array}{c}\text { Número de } \\
\text { cirurgiões-dentistas }\end{array}$ \\
\hline Exodontia & M unicípio & 8 anos & 01 \\
Dentística & M unicípio & 3 anos & 01 \\
\hline
\end{tabular}

dimento do usuário pelos trabalhadores do serviço de odontologia; horário de atendimento odontológico e tempo de atendimento odontológico por procedimento; planejamento e organização das atividades diárias do serviço de odontologia; autonomia profissional do cirurgião-dentista dentro do serviço de saúde.

Para a entrevista semi-estruturada utilizamos um roteiro. Elaboramos questões de forma a que não fosse retratado o nosso conhecimento sobre os cirurgiões- dentistas, ea sua prática odontológica na UBS com o objetivo de não induzir as respostas. As questões:

1) Comente sobre sua experiência no serviço de odontologia da rede básica pública do município de Feira de Santana.

2) Fale sobre as práticas odontológicas desenvolvidas nesta unidade.

3) Fale sobre o processo de municipalização da saúde em Feira de Santana, e qual a influência na prática odontológica.

4) Comente sobre os avanços e as dificuldades encontradas pelo cirurgião-dentista, para desenvolver sua prática odontológica nos serviços de saúde da rede pública.

Portanto, ao optarmos pela entrevista semi-estruturada, possibilitamos aos entrevistados discorrerem sobre o tema proposto, com o intuito de obter dados objetivos e sub- jetivos. As gravações das entrevistas foram transcritas e, posteriormente, ordenadas, classificadas e analisadas.

De posse de todos os dados coletados, construímose (re)construímos o material de análise, explicitado na seqüência.

\section{Análise dos dados}

Para a análise dos dados da pesquisa, utilizamos o método de análise de conteúdo, buscando compreender a fala dos entrevistados, que contemplasse os conteúdos manifesto e latente, presentes nos depoimentos. $A$ análise de conteúdo, segundo Bardin (1979), é um conjunto de técnicas de análise das comunicações, visando, por procedimentos sistemáticos e objeti vos de descrição do conteúdo das mensagens, obter indicadores quantitativos ou não, que permitam a inferência de conhecimentos relativos às condições de produç̧ão/recepção das mensagens.

Ao estabel ecermos relações da proposição de Bardin, inspirado em M inayo (1999), a análise de dad os foi realizada através dos seguintes passos: ordenação dos dados, classificação dos dadose análisefinal. A pesar dea trajetória se apresentar de forma separada e seqüencial, acontece de maneira intercomple- 
mentar edinâmica. N essa perspectiva descrevemos como realizamos, de forma si stemática, a anal ise de conteúdo, no sentido de facilitar uma maior compreensão.

Estabelecidos os núcleos de sentido, selecionamos, pelas UBS A, B e C, os fragmentos das fal as relacionadas à entrevista eà observação da prática. Essa classificação nos permitiu a estruturação de esquemas de análise, e elaboramos a síntese de cada entrevista e de cada observação (vertical ehorizontal), quando identificamos as convergências, divergências, complementaridades e o que era diferente em cada uma das falas e das observações da prática.

Essa classificação nos permitiu eleger o eixo temático central:

A prática odontológica em unidades básicas no processo de municipalização da saúde em Feira de Santana: individual, curativa, autônoma e tecnicista, desenvolvido adiante, na análise e discussão dos resultados.

\section{Análise e discussão dos resultados}

$\mathrm{Na}$ análise final do conteúdo do material coletado procuramos desvendar o conteúdo latente, na perspectiva de compreender o objeto de estudo dentro de um contexto em constantes modificações tecnológicas e sociais, permitindo uma maior compreensão e apreensão da prática odontológica na rede básica pública de Feira de Santana, no processo de municipalização da saúde, sistematizada em seus aspectos de análise, componentes da articulação entre os discursos, as observações e o referencial teórico orientador.

Os aspectos de anál ises que compõem este capítulo são apresentados a seguir.

\section{A municipalização da atenção básica à saúde bucal: "nada começou..."}

Para se entender as estratégias descentralizadoras que vêm sendo desencadeadas desde meados da década de 1970, foi necessário retornar ao movimento por reforma no sistema nacional de saúde, para em seguida estabelecer uma relação com o cenário local de Feira de Santana, situando a prática odontológica nesse contexto.

No inicio da década de 1990, Feira de Santana ficou na dependência da articulação das instâncias governamentais (federal, estadual e municipal) para a transferência de recursos financeiros, contando com a vontade política de seus interlocutores e da falta de mobilização da sociedade civil organizada, sobre as questões de saúde do município. N essa mesma década, conforme refere Assis (1998a; 1998b), entra em cena, na esfera estadual, um governo do Partido da Frente Liberal (PFL), tendo como seu principal interlocutor o governador da Bahia, Antônio Carlos MagaIhães. 0 município de Feira de Santana passa a ser governado pelo Partido do M ovimento Democrático Brasileiro (PM DB), de oposição ao governo do Estado da Bahia. Essa situação política trouxe a retaliação, com bloqueio dos recursos do SUS para o município.

No cenário político nacional, o governo Collor levou o Brasil a uma tragédia sanitária, apesar de a nova Constituição Brasileira assegurar o direito à saúde, e prever a criação de um sistema democrático comprometido com as necessidades da população. Esse governo violentou todos esses princípios, e intensificou um período de desrespeito à ética, à moral e ao interesse público, sem precedentes na história do país. Em outras palavras, houve um agravamento político dramático com efeitos na economia, recessiva e privatizante, caracterizada pel o model o neoliberal. Apesar disso tudo, ocorrem expressivos e bem-sucedidos avanços na reorganização da saúde, cuja implementação é devido aos esforços, principalmente no nível local, tanto de prefeituras, quanto de secretarias municipais de saúde.

0 processo de descentralização das ações de saúde no Brasil teve como base a publicação da Norma O peracional Básica (NOB), em 1991, sem muitas modificações na relação M unicípio-Estado. Nesse mesmo período foi criado o Conselho M unicipal de Saúde em Feira de Santana, composto por representantes de institui ções prestadoras de serviços e de entidades de saúde e o comando a cargo do secretário de Saúde do município.

A partir de 1993 é que o processo começa a tomar corpo, com a operacionalização da $\mathrm{NOB} / 93$, quando os municípios passam a incorporar o Sistema Ú nico de Saúde (SUS), criando diferentes fases para a habilitação, segundo o tipo de gestão pelo qual optasse cada município, cumprindo os pré-requisitos da lei 8.142/1991. Essa lei estabelece uma composição entre critérios populacionais e epidemiológicos para o cálculo das transferências. 
São quatro as situações de transição previstas: Incipiente, Parcial, Semiplena até chegar à Gestão Plena. Em 1995, Feira de Santana se habilita para a gestão incipiente, porém não desencadeia mudanças no processo de gestão local, conforme análise de Assis (1998a, 1998b) sobre o processo de municipalização da saú de. Para esta autora o repasse de recursos continua por instituição ou serviços produzidos, e o modelo de atenção não representou 0 avanço na qualidade esperada e na consolidação do SU S. A situação de Feira de Santana reflete a do Estado da Bahia como um todo. Dos 415 municípios existentes no Estado, $58 \%$ não foram habilitados em nenhuma condição de gestão, e a total idade não al cançou a gestão semiplena; uma vez que esse tipo de gestão poderia conferir autonomia ao município na organização do sistema de saúde, e maior responsabilidade com o resultado de sua ação.

A referida autora afirma, ainda, que houve uma certa omissão dos interlocutores municipais, ao não apresentarem uma proposta concreta que respondesse às necessidades locais, independente da política de saúde definida nas esfer as de poder federal e estadual.

Em 1996, é editada a N OB-01/96 que propõea "Gestão plena com responsabilidadepela saúde do cidadão", com a finalidade de promover e consolidar o pleno exercício, por parte do poder público municipal e do Distrito Federal, redefinindo a função do gestor municipal, e a conseqüente redefinição das responsabilidades dos Estados, do Distrito Federal e da U nião, procurando avançar na consolidação dos princípios orientadores de um sistema universal e igualitário (Brasil, 1997).

Em 1997, assume outro governo municipal em Feira de Santana, e com ele volta a discussão do processo de gestão, que é uma das exigências do processo de mudança do modelo assistencial de saúde, preconizado pelo SUS, em função dos novos critérios adotados pelo M inistério da Saúde aos municípios habilitados com a NOB/ 1996. Este governo adota como proposição a alteração do modelo de gestão e assistencial, vinculado à ação programática e à vigilância em saúde, tendo como eixo condutor às estratégias de territorialização da saúde, em que as prioridades foram no sentido de intervir nas doenças infecto-contagiosas, doenças crônico-degenerativas, saúde da mulher, saúde da criança e recursos humanos (Assis, 1998b).
0 setor de odontologia não foi contemplado no referido plano, com qualquer ação ou reaval iação em suas estratégias de atendimento, até mesmo porque, historicamente, a odontologia dos serviços públicos sempre adotou um modelo tradicional, centrado no atendimento curativo/mutilador, e a situação do município refletia a do cenário nacional.

No entanto, o município de Feira de Santana, de uma maneira geral, mostra avanços no processo de descentralização, tomando iniciativas que envolvem a participação da comunidade, trabalhadores de saúde e instituições locais; nesse sentido, a Secretaria de Saúde organizou um seminário sobre a municipalização da saúde em julho de 1997, com a participação ampliada da sociedade feirense, tendo como desdobramento a elaboração do Plano M unicipal de Saúde (1998-2001).

Tudo isso, reflexo da Reforma Sanitária que vem produzindo reflexões teórico-práticas no reordenamento do Sistema N acional de Saúde, incentivando o controle social com a participação popular, para possibilitar um sistema único, público, universalizado, descentralizado, hierarquizado e regionalizado, e que as ações produzidas tivessem a marca da integralidade.

Ao situarmos a representação dos cirurgiões-dentistas no processo de implantação da municipalização da saúde em Feira deSantana, é preciso estabelecer articulações com a prática odontológica na rede básica publica, até porque este município se encontra na forma de gestão plena da atenção básica.

Os cirurgiões-dentistas entrevistados evidenciaram a sua não-participação no processo da implantação da municipalização da saúde em Feira de Santana; as reuniões com os gestores, para orientação aos profissionais de saúde, não foram significativas e aconteceram em número muito reduzido, assim como não causaram mudanças na assistência odontológica aos usuários da redeSUS.

Apesar de termos clareza de que o processo de municipalização não aconteceu de um momento para o outro, e sim marcado pela trajetória do M ovimento Sanitário, a participação dos cirurgiões-dentistas foi praticamente nula. Estiveram à margem do processo de municipal ização, não demonstrando interesse ou conhecimento sobre o processo. Outro ponto que verificamos, foi a não-definição de uma política de saúde bucal nos planos municipais em nível local com a implantação 
do SUS. Essa questão também está presente no cenário nacional conforme refere Toledo (1991): na elaboração do plano municipal de saúde é necessário garantir a incl usão de todos os componentes refer entes às ações de atividades de saúde bucal, com vistas ao adequado equacionamento de suas questões, uma vez que além da assi stência, na necessidade odontológica da população, é fundamental que se pense na reversão do quadro epidemiológico.

Os depoimentos dos cirurgiões- dentistas que atuam nas U BS são representativos de alguns aspectos da implantação do processo de municipal ização em Feira deSantana:

$N$ ão senti nenhuma diferença na passagem para a municipalização... (CD 2/UBSA)

$N$ ão, não houve nenhum esclarecimento sobre as vantagens ou desvantagens para o cirurgião-dentista, nada disto, apenas na época o secretário fez algumas reuniões antes da municipalização e tal... (CD 9/UBSC)

$\mathrm{Nada}$ aconteceu, apenas vai municipalizar... e pronto, já começou atendendo na engrenagem da municipalização.... ou para mostrar qual a diferença... não senti a diferen ça aqui... (CD 7/UBSC)

As falas dos profissionais nos remetem à questão do significado do sujeito social o que é extremamente controvertido. 0 sujeito também pode ser compreendido como ator social. Para M atus (1987) a forma como estes se relacionam permitem entender a maneira pela qual cada ator define e delimita a situação, ou em outros termos, explica a realidade em função do seu propósito.

Percebemos que o cirurgião-dentista permaneceu e ainda permanece um sujeito alheio ao processo de municipalização, quando afirma que nada aconteceu, e que não sentiu qualquer diferença no desenvolvimento de suas ati vidades práticas, como se o processo da Reforma Sanitária não estivesse em curso e muito menos a estratégia de descentralização via municipal ização da saúde. Q ue sujeito é este? Por que o CD não tenta mudar a sua prática para melhorar 0 seu atendimento em favor dos seus usuários? E que posições estão tomando, quando ficam a mercê de todo um processo?

\section{O funcionamento das UBS no processo de municipalização da saúde de Feira de Santana}

A prática odontológica no processo de municipal ização da saúde está condicionada à quantidade de material odontológico existente na UBS, ignorando o modelo assistencial preconizado pelo SUS. O u seja, a municipalização se resume em ter ou não material para desenvolver as atividades das práticas odontológicas, como vemos nas falas abaixo:

No meu trabalho, eu senti que o material melhorou, o material, assim, por exemplo, algumas coisas, que eu não fazia... existia uma cobrança muito grande só em número, número, até que agora melhorou bastante... (CD 2/UBSA)

... A cho que melhorou, apesar da gente não ter nunca muita dificuldade com as coisas aqui, mas achei que melhorou, não falta, a gente tem luva e sempre tem em quanti dade... tendo o cuidado sempre de fazer a lista quando está acabando a gente já faz, já manda, logo chega... (CD 7/UBSB)

Testa, lembrado por Botazzo (1999), discute que o objeto central do planejamento deve ser contribuir para promover a criação de condições que possibilitem a realização de ações que conduzem a mudanças sociopolíticas e econômicas nos países ( América Latina).

Os CD demonstraram não se preocupar com um planejamento de ações, que possam criar condições de mudança social, e continuam dan do mais atenção ao fato de terem ou não material para o desenvolvimento técnico odontológico; isso foi uma constante nas três UBS estudadas, levando-nos a concluir que não existe um planejamento sistemático das ati vidades odontológicas na rede, como uma forma de articular o político com o técnicocientífico na produção dos cuidados assistenciais em saúde.

As U BS A e B apresentam convergências em relação à aquisição de material de consumo para 0 atendimento odontológico, talvez pelo fato de ambas planejarem a solicitação com base na demanda por atendimento, queé coordenada por uma gerente administrativa local, enquanto na UBS C não existe uma coordenação do trabalho, ficando sob responsabilidade do cirurgião-dentista, lotado na Unidade, o planejamento e a solicitação do material necessário para o desenvolvimento de suas atividades, ou seja, o planejamento se dá no nível individual e de forma assistemática.

as deficiências que a gente tem aqui de, de... a nível de [sic.] saúde municipal, é quando falta material mesmo, que deixa a dese- 
jar... porque na verdade o que eu acho deficiente ainda hoje é justamente esta parte de distribuição do material, de assi stência que a gente tem que estar adulando, correndo atrás na Secretaria de Saúde, e liga e mando e eles não dão atenção, essa coisa toda. (CD 10/U BS 10)

\section{A atenção odontológica centrada na quantidade de procedimentos}

A UBS é pensada como o lugar da ordem, da disciplina dasatividades programáticas, perpassando por um modelo de atenção medicalizante, das políticas médicas. Concretamente, a prática odontológica das UBS é centrada eentendida na quantidade de procedimentos, repercutindo na produtividade. 0 dilema da quantidade versus qualidade começou a ser definido ainda nas escolas de ensino superior, quando professores e alunos tentam, ainda que de forma incipiente, mas moldados pelo modelo flexneriano, um trabal ho de alta produtividade com o sacrifício da qualidade. Podemos denominar essa odontologia de simplificada, na qual, apesar de se enfatizar uma prática preventivista, continua/continuava a priorizar a curativa.

Podemos observar nas falas a seguir, quea quantidadedeprocedimentosainda éuma prioridade:

...são oito pacientes que eu tenho que atender por turno, antes era muito mais... éaquela coisa assi $m$ de produtividade, produtividadee até que agora el es estão melhorando, sentindo, estão vendo que tem a qualidadeno atendimento, como a gente atende o paciente... (CD 2/UBS A)

... trabal hamos ainda em número de procedimentos, e éna faixa de 15 a 20 pacientes... a gente individualiza, mas o número mesmo éde pacientes, mesmo que não faça exodontia, mas conta como consulta... (CD 3/UBSA)

... a gente sempre foi muito cobrada neste ponto de quantidade, eles querem que a gente atenda muita gente... Eu não sei trabalhar aqui entupido de gente... (CD7/UBSB)

... todo dia eles mudam isto, cada dia inventam uma coisa diferente, tem que ter $X$ paciente com $X$ procedimentos... (CD 10/UBSC)

... você deveria ganhar sobre sua produtividade, eu ia me interessar em ter mais pacientes, em buscar mais pacientes, mas como é hoje $40 \%$ para todo mundo. Quem trabal ha equem não trabal ha ganha $40 \%$, então nisto a municipalização não ajudou... (CD 1/UBSA)

\section{A manutenção do modelo curativo tecnicista do atendimento odontológico}

No Brasil, a implantação do SUS está ocorrendo de uma maneira paradoxal. Por um lado, temos uma crise de financiamento do sistema de saúde e do outro, um esforço para que a atenção aconteça dentro de novas perspectivas. Mas, apesar disso, a prática odontológica continua com as mesmas características históricas do início da sua atuação.

0 modelo atual decorre de uma concepção de prática centrada na assistência odontológica ao indivíduo doente, realizada com exclusividade por um sujeito individual, o cirurgião-dentista, no restrito ambiente clínico-cirúrgico, em que a concepção da prática odontológica é enfatizada pelo pensamento de mercado. N esse sentido, para Araújo (1994), o modelo odontológi co caracteriza-se pela dependência externa, na medida em que baseia sua atuação na orientação e na formação de seus recursos humanos, empregando uma tecnologia com insumos e equi pamentos importados e cujas condições pouco reproduzem as existentes no país. A odontologia incorporou o paradigma flexneriano, que defende o corpo humano como uma máquina de natureza exclusivamente biológica.

Diante dessa realidade, acreditamos que é importante que os currículos sejam montados a partir do perfil profissional, que respondam às necessidades da comunidade em que o órgão formador esteja inserido, como parte do projeto local de saúde, articulando ensino e assistência, para que não ten hamos que reduzir a estratégia de mudança de model o via descentralização da saúde a aquisição de recursos. Infelizmente, é o que constatamos nas seguintes fal as:

... Não senti diferença com a municipalização, sempre tivemos os materiais, os mesmos instrumentais para a exodontia, não houve assim, não senti diferença não. (CD 9/UBSC)

... Continua a mesma coisa que antes da municipalização, para mim, a falta de material continua a mesma coisa... (CD 10/U BSC)

... Ainda não avançou nada com a municipalização, éa mesma coisa... se faz hoje a mesma coisa que se fazia há dez anos atrás... (CD 3/UBSA)

... 0 dentista ainda não está preparado para a municipalização, não adianta municipalizar se ele não tiver a consciência da munici- 
palização... (CD 1/UBSA)

Para os cirurgiões-dentistas deFeira de Santana o SUS é uma idéia distante dos acontecimentos da realidade, podemos até dizer um pouco negativistas, não sematerializando como prática social. Daí, ser comum nas falas dos profissionais queo SUS não aconteceu.

Existeuma grande preocupação dos profissionais em relação ao salário, muitos relatam que houvesó a municipalização das ações enão aconteceu uma al teração salarial, e queisso se deveao fato de não existir isonomia salarial nas três instâncias do governo. Na verdade, o governo municipal tem um salário diferenciado do estadual e do federal. Portanto, não existe equiparação salarial na esfera estadual enem uma política derecursos humanos definida que valorize o trabaIhador no seu campo de ação. Os discursos dos profissionais dão conta dessa preocupação:

... 0 líquido chega perto de $R \$ 500,00$ é o mais baixo detodos... (CD 8/UBSA)

... municipalizou o trabalho, mas o salário é pago pelo Estado, hojea gente não sabequem paga, quem éque não paga, o Estado não tem interesse, em aumentar ninguém... (CD 3/UBSA)

... cada vez que entra outra pessoa na secretaria, quer impor determinadas condições e vocêvê que o retorno financeiro não vem, eque o profissional dentro da municipalização, não foi municipalizado, a gente continua sendo funcionário do Estado... (CD 6/UBSB)

Pelos depoimentos podemos perceber a insatisfação do $C D$ quanto à questão salarial, sendo reforçada quando, por ocasião do Relatório Final da 2a Conferência de Saúde Bucal (Brasília, 1993), os profissionais confirmam a inexistência de planos de carreira, cargos e salários, o que contribui para desestimular os servidores. A isonomia salarial ainda não érealidade.

\section{A autonomia eo individualismo profissional do CD : fragmentado, obscurecido e/ou "fetichizado"}

N osserviços desaúde bucal, existeuma resistência dos trabal hadores especializados a se adequarem à mudança da organização do trabal ho. O queexisteé uma ação organizada da corporação, com amparo legal, pois apesar da natureza do trabalho não permite alcançar um grau deracionalização, como sefosse comparada a profissão médica a uma indústria. 0 dentista continua sendo dono do saber de produção e conseqüentemente do tempo de produção (Loureiro, 1998, grifo nosso).
0 individualismo profissional surge como uma das características do cirurgião-dentista, principalmente, por ser esteo planejador e executor de suas atividades. Ao iniciar um procedimento éeleque definetodo o tipo decuidado que vai ser prestado ao usuário e, ao mesmo tempo, não precisa passar por avaliações, ou atémesmo por interferências de outros profissionais da saúde, para que seu trabal ho seja efetuado. O bservamos nas falas dos entrevistados essa característica da prática odontológica:

... o pessoal não interfere, consigo fazer um trabalho realmente humanizado, digamos assim... não para dizer eu tenho que cumprir tal meta. (CD 4/UBSB)

... Eu só faço exodontia. (CD 9/UBSC)

Eu só faço restauração, não faço extração... (CD 2/UBSA)

... a gente vem trabalha, sabe o quetem defazer, aquilo, atender as pessoas, o material está aí, fazemos nosso trabal ho epronto... (CD 7/UBSB)

De lá para cá, não mudou nada não; só mudou o meu esquema de atendimento em rel ação aos pacientes, só... (CD 10/UBSC)

O cirurgião-dentista desenvolvesuas atividades deforma autônoma, independentee individualizada, quando demonstra não sofrer interferências externas da organização em que está inserido, ou seja, é ele quem decide como será seu trabalho, usando da sualiberdadee demonstrando ser o "dono" do seu saber técnico. Essa questão éapontada por M endes (1999) ao se referir à prática médica (a qual se constitui em modelo dominantee influenciador das outras práticas), afirmando o profissionalismo está associado à autonomia profissional, expressa na liberdade do médico em decidir, sem interferências externas, 0 que deveser feito, transformando- o em juiz das próprias ações, o que deriva do monopólio do conhecimento técnico.

\section{Considerações finais}

Consideramos este estudo de relevância, uma vez que nos proporcionou uma reflexão sobre a prática odontológica desenvolvida nas U BS de uma realidade específica que articula as práticas no cenário nacional no processo de implantação do Sistema Ú nico de Saúde.

Destacamos, aqui, o pressuposto teórico desse estudo, a prática odontológica tem raízes históricas, culturais e sociais na formação do cirurgião-dentista, pautada no modelo flexneriano ou medicina científica, consti- 
tuindo-se em uma prática individual, curativa, tecnicista, especializada e biologicista, eao relacioná-lo com os depoimentos dos entrevistados (cirurgiões- dentistas), com a observação, no contexto do município de Feira de Santana, pudemos perceber que os resultados obtidos apontam que:

- Apesar de o município ter incorporado os princípios e as diretrizes norteadoras do SUS, através de um processo lento, houve pouca vontade política. $O$ setor de odontologia continua exercendo uma atividade curativa, baseada no modelo de atenção à saúde bucal tradicional/ mutilador, e com poucos avanços na prevenção à saú de bucal. Portanto, refletindo ainda o modelo flexneriano, permanece como uma prática individual, curativa, tecnicista e autônoma.

- O estabelecimento de uma consciência profissional é, portanto, de fundamental importância na construção de uma nova concepção de "saúde bucal", em que a eqüidade é

\section{Referências bibliográficas}

Araújo ME 1994. A saúde bucal no Estado de São Paulo com a implantação do Sistema Ú nico de Saúde uma análise. Dissertação de mestrado em odontologia, Faculdade de O dontologia/USP, São Paulo.

Arouca AA 1988. Reforma sanitária brasileira. Tema Radis 11:24, nov.

Assis M M A 1998a. A municipalização da saúde: intenção ou realidade? Universidade Estadual de Feira de Santana, Feira de Santana.

Assis M M A 1998b. As formas de produção dos serviços de saúde: o público e o privado. Ribeirão Preto, 1998b. 313p. Tese de doutorado em enfermagem, Escola de Enfermagem de Ribeirão Preto/USP, Ribeirão Preto.

Bardin L 1979. Análise de conteúdo. Edições 70, Lisboa.

Brasil. Constituição, 1988. Constituição da República Federativa do Brasil. Empresa Gráfica da Bahia, Salvador.

Brasil. M inistério da Saúde 1999. Secretaria de Assistência à Saúde. M anual para a O rganização da Atenção Básica Saúde. Brasília.

Botazzo C 1999. U nidade Básica de Saúde: a porta do sistema revisitada. Edusc, Bauru.

Cohn A \& Paulo EE 1999. Saúde no Brasil: políticas e organização de serviços. Hucitec, São Paulo.

Conferência Nacional de Saúde Bucal (2ạ) 1993. Relatório final. M inistério da Saúde, Brasília.

Feira de Santana 1999. Plano M unicipal de Saúde-19982001. Secretaria M unicipal de Saúde, Feira de Santana.

Fernandez M T 2001. A descoberta da boca. Revista Bra- um dos princípios preconizados pelo SU S, e deve ser buscada pelo reconhecimento das desigualdades existentes e no desenvolvimento de ações específicas, direcionadas aos vários grupos populacionais.

- Nas observações práticas da pesquisa de campo, identificamos obstáculos que impedem ou dificultam o acesso do usuário ao setor de odontologia, e, em outros momentos, são as próprias condições do serviço odontológico que funcionam como barreira para 0 atendimento ao usuário. Portanto, esse serviço continua refletindo os interesses na manutenção do um modelo político e econômico centralizador nas ações de saúde.

Acreditamos que para (re) construirmos uma nova prática odontológica seja necessário, como agentes de mudanças, sabermos que esse (re)fazer da prática odontológica é um desafio cotidiano, eque envolve não só o profissional como também a política de saúde, e outros segmentos da sociedade.

sileira de 0 dontologia. 9(1):6-11, fev/mar

IBGE 1998. Feira de Santana. Rio de Janeiro.

IBGE 2000. Feira de Santana. Rio de Janeiro.

Loureiro CA 1998. A inversão da atenção em saúde bucal. In EV M endes (org.). A organização da saúde no nível local. Hucitec, São Paulo.

M atus RE, Li efer CE, H urvitz AI 1987. U se of plasmapheresis and chemotherapy for treatment of monoclonal gammopathy associated with Erlichia canis infection in a dog. Journal American 1:190: 13021304.

M endes EV 1985. A evolução histórica da prática médica, suas implicações no ensino, na pesquisa e na tecnologia médicas. PUC/M G-Finep, Belo H orizonteBrasília.

M endes EV 1999. U ma agenda para a saúde. (2a ed.). Hucitec, São Paulo.

M inayo M CS \& Sanches O 1998. M CS Quantitativoqualitativo. Cadernos de Saúde Pública/Reports in Public H ealth 9(3):254-255.

Minayo MCS 1999. O desafio do conhecimento: pesquisa qualitativa em saúde. (6a ed.) HucitecAbrasco, São Paulo-Rio de Janeiro.

M inayo M CS (org.) 2000. Pesquisa social: teoria, método e criatividade. (17a ed.). Vozes, Petrópolis.

Rivera FJU (org.) \& Matus C 1989. Planejamento e programação em saúde: um enfoque estratégico. Cortes-Abrasco, São Paulo.

Toledo JPG 1991. A saúde bucal no Estado de São Paulo - das A ções I ntegradas de Saúde ao Sistema Ú nico de Saúde. CADAIS/SES-SP, São Paulo. (M imeo).

Artigo apresentado em 3/10/2002

A provado em 11/11/2002

Versão final apresentada em 16/12/2002 